\title{
Platinum-resistance and AKT Over-expression in Ovarian Cancer
}

\section{Jens C. Hahne}

Centre for Molecular Pathology, The Institute of Cancer Research, 15 Cotswold Road, Sutton, Surrey, SM2 5NG, United Kingdom

\section{Abstract}

Ovarian cancer is among the most common cause of cancer death and ranks first in the number of deaths each year in the field of gynaecological malignancies. This is due to its late diagnosis and the development of chemoresistance. Platinum derivates, including cisplatinum and carboplatinum in combination with paclitaxel, are the first-line chemotherapeutic agents. Platinum derivates intercalates irreversibly into the DNA and creates inter- and intra-strand DNA cross-links. During cell division, platinum-DNA-adducts block the replication machinery, inducing DNA damage and apoptosis. Nearly all patients respond to first line chemotherapy before it comes later to recurrence of the disease. At time of recurrence, tumours are usually more aggressive, form metastasis in secondary tissues and acquire resistance to conventional chemotherapeutics. Drug resistance is a common problem in tumour therapy not only restricted to ovarian cancer. This is characterized by gene mutations, increased DNA repair, reduced drug efficacy and enhanced drug clearance and detoxification. Up to now the complex molecular mechanism of chemoresistance is not well understood but increasing evidence points towards AKT over-expression and alteration of the PI3K/AKT/mTOR cascade as a central mechanistic reason for this resistance.
\end{abstract}

\section{Publication History:}

Received: February 13, 2014

Accepted: April 28, 2015

Published: April 30, 2015

\section{Keywords:}

PI3K-cascade, MAPK/ERKcascade, Gynaecological tumours, platinum-resistance, Ovarian cancer

\section{Introduction}

In 2012 14,1 million new cancer cases have been diagnosed, cancer caused the death of 8,2 million patients and 32,6 million people are living with cancer (within 5 years of diagnosis) world-wide [1].

Gynaecological tumours are among the most common cause of cancer death and currently causing more than 100,000 deaths per year [2]. The highest tumour-associated mortality of gynaecological malignancies is related to ovarian cancer [2]. Therefore ovarian cancer is an important public health problem and there has been no appreciable improvement in survival for women with ovarian cancer over the past 40 years. The survival of ovarian cancer is poor and more than $70 \%$ of cases are diagnosed at late stage.

In ovarian cancer treatment platinum-based chemotherapy plays a pivotal role as first line chemotherapy option in combination with taxane [3]. Therefore platinum-resistance is the most crucial problem for treating ovarian cancer and there is a definite clinical need to develop new treatment strategies to overcome platinum resistance.

Increasing evidence points towards AKT over-expression and alteration of the $\mathrm{PI} 3 \mathrm{~K} / \mathrm{AKT} / \mathrm{mTOR}$ cascade as a mechanistic reason for this resistance.

This review provides a short overview of the PI3K/AKT/mTOR signalling network, the interplay with the Ras/Raf/MEK/ERK signal cascade and discusses the rationale for targeting the PI3K/ AKT/mTOR pathway in cancer with a special focus on tumour immmunological aspects. A better understanding of the molecular mechanism causing cancer therapy-resistance could most probably result in new therapeutic options able to revert chemotherapy resistance and enhance sensitivity to platinum-based chemotherapy drugs in ovarian tumours.

\section{Phosphatidylinositol-3-Kinase (PI3K)/AKT Signal Transduction Pathway}

One of the most frequently altered signalling pathways involved in cancer as well as in resistance development especially in ovarian cancer is the $\mathrm{PI} 3 \mathrm{~K} / \mathrm{AKT} / \mathrm{mTOR}$ pathway (Figure 1).

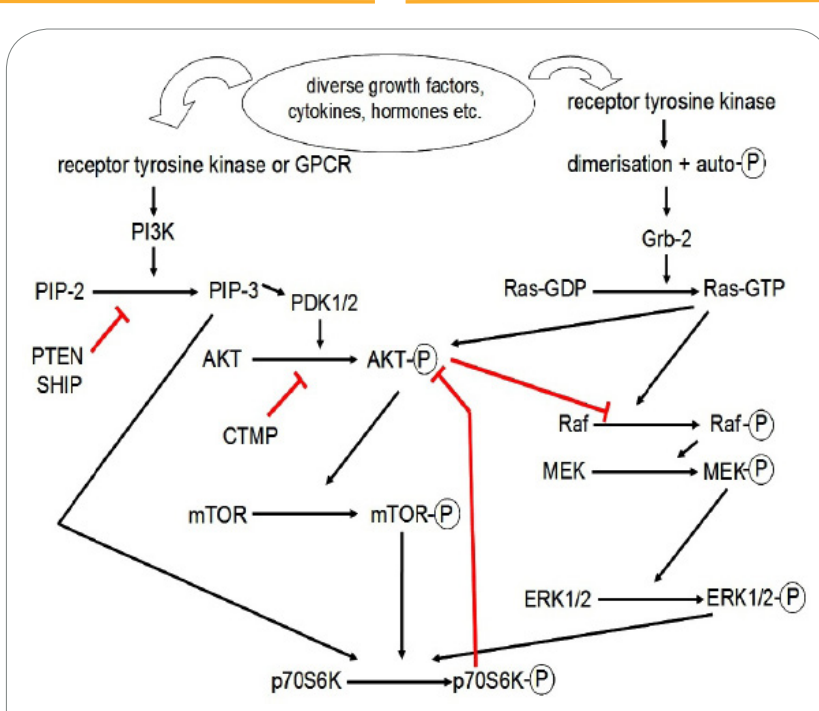

Figure 1: Schematic overview of PI3K/AKT/mTOR and RAS/ RAF/MEK/ERK signal transduction pathways.

The central proteins of both signal transduction pathways are shown together with their activation and repression interaction.

This pathway is a central signal transduction pathway, which transmits signals from multiple cell surface receptors to transcription factors in the nucleus [29-31]. Furthermore there exist several direct interactions between PI3K/AKT- and Ras/Raf/MEK/ERK-signal transduction pathways (Figure 1) [32].

The Ras/Raf/MEK/ERK signal cascade can be activated via binding of several extracellular components like growth-factors or adhesion

"Corresponding Author: Dr. Jens C. Hahne, Centre for Molecular Pathology, The Institute of Cancer Research, 15 Cotswold Road, Sutton, Surrey, SM2 5NG, United Kingdom, Tel.:+4402089156633 ; E-mail: jens.hahne@icr.ac.uk

Citation: Hahne JC (2015) Platinum-resistance and AKT Over-expression in Ovarian Cancer. Int J Gynecol Clin Pract 2: 110. doi: http://dx.doi. org/10.15344/2394-4986/2015/110

Copyright: ( 2015 Hahne. This is an open-access article distributed under the terms of the Creative Commons Attribution License, which permits unrestricted use, distribution, and reproduction in any medium, provided the original author and source are credited. 
molecules to receptor tyrosine kinases [28]. The receptor tyrosine kinase activation results in dimerisation and auto-phosphorylation [33]. The growth-receptor-bound-protein 2 (Grb2) binds to the receptor dimer and causes transformation of Ras-GTPase from an inactive state with bound GDP into active state with bound GTP. The activated Ras kinase binds and activates than the serine-threoninekinase Raf. Phosphorylated and by this activated Raf in turn activates MEK via phosphorylation and the phosphorylated MEK has the capacity for ERK and MAPK activation [28,34-36]. ERK1 and ERK2 phosphorylate a huge range of nuclear and cytoplasmatic substrates resulting in initiation of different cellular responses involved in proliferation, differentiation, cell cycle progression and cell death [33].

Crosstalk Between the PI3K/AKT- and Ras/Raf/MEK/ERKSignal Transduction Pathways

Different studies have shown that an over-expression of AKT results in down-regulation of ERK [12,37]. Furthermore crosstalk between these pathways was observed after treatment of cells with pharmaceutical inhibitors of PI3K which decreased ERK activity [3841]. This interaction suggests cooperation between the two pathways in order to determine functional outcomes.

The Ras superfamily of small G proteins is one of the connecting points between the PI3K/AKT/mTOR- and Ras/Raf/MEK/ERKsignal transduction cascade. It was shown that Ras is involved in activation of PI3K $[32,42,43]$.

Furthermore it was demonstrated that also the PI3K/AKT-pathway controls the Ras/Raf/MEK/ERK-signal transduction cascade; phosphorylated AKT decreased the Raf activity [43-45].

The protein $\mathrm{p} 70 \mathrm{~S} 6 \mathrm{~K}$ was identified as another connecting point between the PI3K/AKT/mTOR- and Ras/Raf/MEK/ERK-signal transduction cascade $[46,47]$. The serine-threonine-kinase p70S6K is downstream of PIP3 and PDK1 in PI3K/AKT/mTOR-pathway and a direct target of mTOR and also a direct target of ERK1/2 [47,48]. Of special interest is that activation of p70S6K is involved in feed-back inhibition of the PI3K/AKT/mTOR-signal transduction cascade [49].

\section{Alteration of the PI3K/AKT/mTOR-signal Transduction Pathway in Tumours}

Recent studies indicate that numerous components of the PI3K/ AKT/mTOR-pathway are targeted by amplification, mutation and translocation more frequently than any other pathway in cancer patients with resultant activation of this pathway [22].

Both genetic and biochemical data suggest that activation of the $\mathrm{PI} 3 \mathrm{~K} / \mathrm{AKT} / \mathrm{mTOR}$ survival pathway contributes to ovarian cancer development and tumour genesis [17]. Such activation is caused by different mechanisms and one mechanism is somatic alterations in PI3KCA that have been found in a substantial fraction of ovarian cancers [50]. PIK3CA amplifications are present in $40 \%$ of ovarian cancers [21]. Furthermore, activation of PI3K/AKT/mTOR signal transduction pathway is caused by mutations in the gene coding for PIK3CA. Frequencies of PIK3CA mutations in subtypes of ovarian cancer are shown in table 1 and in table 2 the frequencies of specific PIK3CA mutations in ovarian cancer are summarized.

Another alteration that results in increased activity of the PI3K/ $\mathrm{AKT} / \mathrm{mTOR}$ pathway is PTEN loss-of-function. PTEN loss is observed in about $7 \%$ of all ovarian cancer cases and it seems to be more common in type I ovarian tumours [51-56].

\begin{tabular}{|l|l|l|l|l|l|}
\hline $\begin{array}{l}\text { Ovarian } \\
\text { cancer }\end{array}$ & \multicolumn{2}{|l|}{ Type I } & \multicolumn{2}{l|}{} & Type II \\
\hline & $\begin{array}{l}\text { Low } \\
\text { Grade } \\
\text { Serous }\end{array}$ & $\begin{array}{l}\text { Clear } \\
\text { Cell }\end{array}$ & Endometrioid & Mucinous & $\begin{array}{l}\text { High } \\
\text { Grade } \\
\text { Serous }\end{array}$ \\
\hline $\begin{array}{l}25 \%(\mathrm{a}) \\
12 \%(\mathrm{~m})\end{array}$ & $5 \%$ & $35-50 \%$ & $20 \%(\mathrm{~m})$ & Rare & $3 \%(\mathrm{~m})$ \\
{$[106]$} & {$[137]$} & $\begin{array}{l}(\mathrm{m}) \\
{[138,} \\
139]\end{array}$ & {$[138]$} & & $\begin{array}{l}20 \%(\mathrm{a}) \\
{[140]}\end{array}$ \\
\hline
\end{tabular}

Table 1: Frequency of PIK3CA molecular alteration (gene mutations (m) and amplification (a)) in ovarian cancer.

\begin{tabular}{|l|l|l|l|}
\hline Exon & $\begin{array}{l}\text { Amino Acid } \\
\text { Change }\end{array}$ & $\begin{array}{l}\text { Nucleotide } \\
\text { Change }\end{array}$ & $\begin{array}{l}\text { Frequency Among PIK3CA- } \\
\text { Mutated Ovarian Cancer }\end{array}$ \\
\hline 9 & E542K & $1624 \mathrm{G}>\mathrm{A}$ & $10.2 \%$ \\
\hline & E545K & $1633 \mathrm{G}>\mathrm{A}$ & $12.6 \%$ \\
\hline & E545A & $1634 \mathrm{~A}>\mathrm{C}$ & $12.6 \%$ \\
\hline & Q546K & $1636 \mathrm{C}>\mathrm{A}$ & $1.8 \%$ \\
\hline 20 & H1047R & $3140 \mathrm{~A}>\mathrm{G}$ & $41.4 \%$ \\
\hline & H1047L & $3140 \mathrm{~A}>\mathrm{T}$ & $2.8 \%$ \\
\hline
\end{tabular}

Table 2: Frequencies of specific mutations in PIK3CA. These mutations usually occur within two hotspot-areas within the helical domain (encoded by exon 9) and the kinase domain (encoded by exon 20). Data are according to COSMIC database

For AKT a point-mutation in the PH-domain has been detected in ovarian cancer [57]. This point-mutation results in conformational change of the PH-domain so that AKT can be activated without the presence of PI3K [57].

Also the deregulation, mutation or over-expression of cell surface receptors can result in an increased activity of the PI3K/AKT/mTOR signalling pathway in ovarian cancer [58]. Furthermore Ras mutations are found in $20 \%$ of low-grade ovarian cancers [59]. Because of the fact that Ras has been shown to activate both the Ras/Raf/MEK/ ERK and the PI3K/AKT/mTOR pathway, mutation of Ras should theoretically activate both pathways simultaneously. But up to now it is not evaluated in detail if Ras mutations result also in an increased activity of the PI3K/AKT/mTOR-signalling pathway. Nevertheless one study exists that demonstrates that some Ras mutations result in deregulated PI3K and downstream AKT activation [60]. Beside Ras mutations also the over-expression of different other proteins e.g. Rab25 [61], Twist2 [62] or MyD88 [63] seems to result in activation of AKT. The fact that AKT can be activated by a huge number of different proteins underlines the importance of AKT under physiological and pathophysiological conditions. Nevertheless, in human specimens of ovarian cancer AKT was found to be activated in 68\% [64].

\section{Effects of Altered PI3K/AKT/mTOR-signal Transduction Pathway in Tumours}

As mentioned before, AKT is an important junction known to regulate various cellular pathways that promote cell survival, cell proliferation, angiogenesis and invasion. Furthermore, the epithelialmesenchymal-transformation, an important step for tumour metastasis, has been shown to be related to AKT activation [65]. Deregulation of components of the PI3K/AKT-cascade not only contributes to ovarian cancer development and tumourigenesis but also to chemotherapeutic drug and radiation resistance as it was recently shown $[4,20,66-81]$. The sensitivity of cells to radiation and 
chemotherapeutic drug-induced apoptosis is determined by the balance between cellular survival and apoptosis $[4,14]$. Due to the well-known anti-apoptotic role of AKT, an AKT over-expression in cancer cells might most probably mediate resistance to radiation and chemotherapy.

Beside the PI3K/AKT/mTOR signalling cascade other general mechanisms of resistance exist. In this review other possibilities of platinum-resistance will be only shortly mentioned. Some publications describe that platinum-resistance can be also caused by differential expression of microRNAs [82-84] as well as by detoxification of bioactive platinum-complexes by sulphur-containing peptides or proteins, cellular compartimentation and increased DNA repair [66]. Furthermore diminished drug accumulation caused by reduced uptake or increased efflux of platinum compounds via heavy metal transporter can result in platinum therapy failure [66].

Recently it was demonstrated that microRNAs involved in platinumresistance are directly involved in regulation of PTEN, AKT or other downstream molecules of the PI3K/AKT pathway [85-92].

The fact that members of the PI3K/AKT/mTOR pathway are regulated by microRNAs involved in platinum-resistance emphasises the importance of the $\mathrm{PI} 3 \mathrm{~K} / \mathrm{AKT} / \mathrm{mTOR}$ signalling cascade as therapeutic target. Therefore inhibition of PI3K/AKT/mTOR signalling in ovarian carcinomas seems to be a promising target to enhance the efficacy of anticancer agents such as cisplatinum and to pathway are regulated by microRNAs involved in platinum-resistance emphasises the importance of the PI3K/AKT/mTOR signalling cascade as therapeutic target. Therefore inhibition of PI3K/AKT/mTOR signalling in ovarian carcinomas seems to be a promising target to enhance the efficacy of anticancer agents such as cisplatinum and to overcome the resistance of tumour cells against therapy. This hypothesis was tested in different preclinical in-vitro studies. Cancer cell lines are frequently used as invitro tumour models especially for analyzing and study of the effects related to a single gene. Today approximately 100 ovarian cancer cell lines are publicly available [93]. Some of these cell lines are known to be platinum resistant e.g. SKOV-3/DDP and Caov-3. Among the huge variety of ovarian cancer cell lines there are also the parental A2780 cells and the cisplatinum-resistant A2780cis cells [94]. Both cell lines are p53 and K-Ras wild-type and they have the same genetic background. The cisplatinum-resistant A2780cis cell line has been developed by chronic exposure of the parental cisplatinum-sensitive A2780 cell line to increasing concentrations of the chemotherapeutic agent [94]. These cell lines are excellent models for analyzing the molecular basis for cisplatinum resistance in ovarian cancer [72-74, 95-98]. According to these studies AKT over-expression in ovarian cancer is at least one important reason for platinum resistance in this tumour entity $[61,72,99]$. It was shown that $\mathrm{AKT}$ protein expression is strong increased in cisplatinum-resistant A2780cis cell line compared to the parental A2780 cell lines [72,73]. The platinum resistance in A2780cis cell line could be overcome by AKT down-regulation via siRNA [72]. This was demonstrated in several functional in-vitro assays, e.g. clonogenicity assays, irradiation assays, determination of the apoptosis rate, and the cytotoxicity of cisplatinum was addressed in proliferation assays. Stable increase of AKT amount (AKT+) in the cell lines results in an increased $\mathrm{IC}_{50}$ value for cisplatinum whereas a stable decrease of AKT (AKT-) results in an increased accessibility for cisplatinum treatment [72] (table 3). Taken together it was shown in two cell lines with the same genetic background that AKT-overexpression rendered platinum-sensitive A2780 cells platinumresistant. Still more importantly, platinum-resistance of A2780cis cells could be reversed by down-regulation of AKT [72]. FACS analysis demonstrated that cisplatinum induces cell cycle arrest predominantly in the $\mathrm{S}$ and the G2/M phase but also in the G1 phase regardless of the AKT-expression status. However, required doses of cisplatinum were substantially higher in cell lines with AKT-over-expression $[72,100]$.

\begin{tabular}{|l|l|}
\hline & $24 \mathrm{~h}$ \\
\hline $\mathrm{A} 2780$ & $9.4+0.6$ \\
\hline $\mathrm{A} 2780 \mathrm{cis}$ & $>40.0$ \\
\hline $\mathrm{A} 2780 \mathrm{AKT}+$ & $31.0+0.3^{*}$ \\
\hline A2780 AKT - & $7.6+0.2^{*}$ \\
\hline A2780cis AKT + & $>40.0$ \\
\hline A2780cis AKT- & $18.9+0.3^{\star}$ \\
\hline
\end{tabular}

Table 3: $\mathrm{IC}_{50}$ of ovarian cancer cell with and without overexpression and downregulation of Akt subsequent to treatment with cisplatinum . Cytotoxicity was determined by MTT- assay. Statistically significant differences $\left({ }^{*}=\mathrm{p}<0.005\right)$ exist between A2780, A2780 AKT+ and A2780 AKT- and between A2780cis and A2780cis AKT-. All data were previously published in "Oncology Reports" [72] and is reprinted by permission of Spandidos Publications (C2012.

As already mentioned above the sensitivity of cells to radiation and drug-induced apoptosis is determined by the balance between proapoptotic and anti-apoptotic protein expression $[4,14]$. Therefore the effect of the PI3K/AKT cascade on proapoptotic protein like BAD, a known substrate of AKT, has been studied in both cisplatinum-resistant Caov-3 and -sensitive A2780 human ovarian cancer cells [101]. Treatment of Caov-3 and A2780 cells with cisplatinum stimulated the activation of AKT, and the PI3K inhibitor wortmannin blocked the cisplatinum-induced AKT-activation. Cisplatinum treatment also stimulated phosphorylation of BAD at the Ser-112 and Ser-136 sites in Caov-3 and A2780 cells. Whereas phosphorylation of BAD at Ser136 was blocked by treatment with wortmannin, its phosphorylation at Ser-112 was blocked by a MAP/ERK kinase inhibitor, PD98059 [102]. Exogenous transient expression of a dominant-negative AKT in both Caov-3 and A2780 cells decreased cell viability after treatment with cisplatinum. In contrast, no sensitization to cisplatinum was observed in cells expressing wild-type AKT. These findings suggested that cisplatinum-induced DNA damage causes the phosphorylation of $B A D$ via extracellular signal-regulated protein kinase (ERK) cascade and via a PI3K/AKT/mTOR cascade. Inhibition of either of these cascades sensitizes ovarian cancer cells to cisplatinum, thus providing further evidence that the AKT-pathway is involved in cisplatinumresistance in ovarian cancers [101]. Additional results suggest that AKT confers platinum-resistance, in part, by modulating the direction of p53 on the caspase-dependent mitochondrial death pathway [103]. Thus, in ovarian cancers p53 is a determinant of platinum sensitivity and AKT contributes to chemoresistance, in part, by attenuating p53mediated PUMA upregulation and phosphorylation of p53 [104]. Recent results suggest that in platinum sensitive ovarian cancer cells, cisplatinum-induced apoptosis can also proceed, in part, via a caspase-independent mechanism involving apoptosis inducing factor (AIF), and that AKT activation additionally confers resistance to cisplatinum-induced apoptosis by blocking this pathway [103].

The anti-tumour effect of tangeretin, a citrus flavonoid known to inhibit cancer cell proliferation, was investigated in combination with cisplatinum in in-vitro models of A2780/CP70 and 2008/C13 cisplatinum-resistant human ovarian cancers [105]. Pretreatment of cells with tangeretin before cisplatinum treatment synergistically inhibited cancer cell proliferation. Interestingly, phospho-AKT and its 


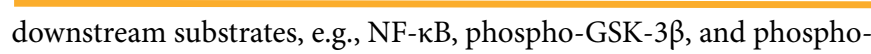
$\mathrm{BAD}$, were down-regulated upon tangeretin-cisplatinum-treatment. The tangeretin-cisplatinum-induced apoptosis in A2780/CP70 cells was increased by PI3K inhibition and siRNA-mediated AKT silencing, but reduced by over-expression of constitutively activated AKT [105]. Although the overall results can only be interpreted with caution, as natural compounds such as tangeretin may display different effects apart from AKT-inhbition, tangeretin exposure preconditions cisplatinum-resistant human ovarian cancer cells for cisplatinum induced cell death. This effect may occur through downregulation of the PI3K/AKT/mTOR signalling pathway. In addition to these in-vitro studies, in a series of 98 patients with amplification of PI3K, an upstream component of the AKT-pathway was associated with resistance to platinum-based chemotherapy [106]. Accordingly, Woenckhaus et al. found that PIK3CA amplification was a strong predictor for early tumour associated death in ovarian cancer patients [107].

Recent work evaluated the anti-tumour efficacy of the AKT inhibitor perifosine in platinum-sensitive and -resistant human ovarian cancer cells $[70,108]$. In different ovarian cancer cell lines and in-vivo experiments it was possible to show that cells with higher levels of phospho-AKT are more sensitive to treatment with AKT-inhibitor perifosin. Furthermore, coincubation with perifosine sensitized A2780cis cells to treatment with cisplatinum. AKTinhibitor perifosine has already been tested in phase II studies in patients with breast, prostate, pancreatic, head and neck cancer, malignant melanoma, multiple myeloma, colorectal cancer and soft tissue sarcoma [109-115]. A recent phase I study with perifosine combined with radiotherapy performed in patients with advanced solid tumours has shown preliminary evidence of anti-cancer activity, including complete responses [116]. Thus, perifosine seems to be an attractive compound for further clinical studies in tumour entities, such as platinum-resistant ovarian cancers.

\section{Role of AKT Expression Level in Tumour Cells in Regard to NK Killing}

Another aspect in tumour diseases is the role of the immune system. As survival is strongly influenced by immunological parameters, immunotherapeutic strategies appear promising and during the last years the interest in tumour immunology has increased. A necessary prerequisite for immunotherapy in patients is a better understanding of the interaction between ovarian tumour cells and cells of the immune system especially natural-killer (NK)-cells. NK-cells are a critical component of the innate immune response against infectious pathogens and malignant transformation $[117,118]$. NK-cells mediate there activity through the elaboration of various cytokines as well as through direct cytolytic activity. However, unlike adaptive immune cells, which utilize specific clonal recognition receptors, NK-cell activation depends on a complex balance between activating and inhibitory signals $[119,120]$. NK-cells play an important role in immune surveillance and coordinating responses of other immune cells. Most tumour cells express surface molecules that can be recognized by activating receptors on NK-cells [121]. The expression of these receptors make such cells susceptible to endogenous NKcells, but malignant cells have developed mechanisms to evade these mechanisms of innate immune surveillance [122-124]. In patients with cancer, it is presumed that tumour cells have developed mechanisms to suppress NK-cell activation and resist lysis by endogenous NK-cells, but the molecular basis for target resistance is not well understood.
AKT seems to play also an important role in immune modulation. Recent studies have confirmed that AKT can regulate the development and functions of innate immune cells [125]. In this review only the role of activated AKT in tumour cells in regard to NK-cells will be addressed.

The PI3K/AKT/mTOR pathway regulates multiple cellular processes which underlie immune responses against pathogens or malignant cells $[126,127]$. Conversely, there is accumulating evidence that the $\mathrm{PI} 3 \mathrm{~K} / \mathrm{AKT} / \mathrm{mTOR}$ pathway is involved in the development of several malignant traits of cancer cells as well as their escape from immunity [128]. In some studies the interactions between cancer cells and natural-killer (NK)-cells have been enlightened [73,95,129-131]. Modified FATAL assay was used for determining the killing efficiency of NK-cells in regard to ovarian cancer cell models in-vitro. Therefore parental A2780 cells and the cisplatinum resistant A2780cis human ovarian cancer cells have been used. The efficiency of NK-cell mediated cell lysis differs between A2780 cells and the cisplatinum-resistant A2780cis cells. A2780cis cells are less accessible for NK-cell mediated killing $[73,95]$. This finding is in agreement with a report by Bellucci et al., using a lentiviral shRNA library targeting $>1,000$ human genes they identified 83 genes that promote target cell resistance to human NKcell-mediated killing [132]. Many of the genes identified in this genetic screen belong to common signalling pathways including members of the AKT/PI3K/mTOR pathway such as PIK3CA and PIK3CB [132]. The comparison of cancer cell lines A2780 and A2780cis revealed that the observed differences with regard to NK-cell mediated killing are most probably based on two mechanisms. First of all the observed increased expression of anti-apoptotic genes (especially ciap-1 and -2) in A2780cis cells compared to A2780 cells most probably renders A2780cis cells more resistant against apoptosis. Second the CD112 ligand for NK-cell receptor DNAM-1 was expressed at a reduced level in A2780cis cells but ligands for the NK-cell receptor NKG2D, e.g. MICA/B, were expressed more strongly in the platinum-resistant cells compared to parental A2780 cells [73]. A2780cis cells express lower levels of TIMP-3 the inhibitor of MICA/B shedding. At the same time the proteases for shedding are expressed which result in a net increase of soluble MICA/B in A2780cis cell cultures [73]. It is well known that cleaved MICA/B protect cells against NK mediated cell killing $[73,133,134]$. Therefore, it is very likely that most probably the increased amount of soluble MICA/B is responsible for the lower killing rate of platinum-resistant A2780cis cells compared to their parental A2780 cells [73]. Previously it was demonstrated that PI3K/ $\mathrm{AKT} / \mathrm{mTOR}$ pathway is involved in inducing MICA/B expression in breast cancer cells [135]. This finding seems to be a more general effect of an induced PI3K/AKT/mTOR signal transduction way; also in ovarian cancer cells with an increase in phosphorylated AKT/ activated PI3K/AKT/mTOR pathway higher MICA/B expression has been detected [73]. Recently it was demonstrated that treatment of tumour cells with JAK inhibitors increased their susceptibility to NK-cell mediated killing [132]. The authors concluded that common signalling pathways can regulate susceptibility of human tumour cells to killing by immunologic effector cells and that small molecule inhibitors of these kinases may have important immunologic effects in-vivo [132]. Whether in analogy inhibition of PI3K/AKT/mTOR pathway renders the platinum-resistant A2780cis cells accessible for NK-cell mediated killing must be evaluated in further studies. Only the first steps towards the characterization of the molecular basis for resistance mechanisms in ovarian cancer with different AKT expression levels regarding NK-cell mediated killing are done [73,95]. 
Citation: Hahne JC (2015) Platinum-resistance and AKT Over-expression in Ovarian Cancer. Int J Gynecol Clin Pract 2: 110. doi: http://dx.doi.org/10.15344/2394$4986 / 2015 / 110$

\section{Conclusion}

Alterations of the serine/threonine kinase AKT/PKB pathway have been detected in several human malignancies including ovarian cancer [136]. AKT has a broad range of downstream effectors that regulate cell processes such as cell growth, cell cycle progression, survival, migration, epithelial-mesenchymal-transformation and angiogenesis [76]. Furthermore AKT seems to be able to influence directly the immune resistance of malignant cells e.g. ovarian tumour cells [73, 95,129-131]. Comparison of parental and immuneresistant ovarian tumours revealed that AKT is highly activated in the immune-resistant tumours. The observed resistance against apoptosis was found to be associated with the up-regulation of anti-apoptotic molecules [73].

The AKT pathway is a promising target for cancer therapy, as it is a main nodal point where extracellular and intracellular oncogenic signals are integrated. Due to the key role of AKT in malignant transformation numerous inhibitors of the AKT-pathway have been developed, and are currently in various stages of clinical development [32]. In human specimens of ovarian cancer AKT was found to be activated in 68\% [136] and PI3K, an upstream component of the AKT-pathway, was found to be mutated in $12 \%$ of the cases [64]. Recent evidence has shown that overactivation of the PI3K/AKT/mTOR-pathway may be associated with platinum resistance $[20,70-72,78,95]$. It was demonstrated that parental A2780 cells become platinum resistant by over-expression of AKT and that platinum resistance in A2780cis cells can be overcome by transfection with siRNA down-regulating AKT [72]. Due to different deregulation that can occur in the PI3K/AKT/ mTOR pathway, as outlined above, there will exist in tumour patients most probably differences that should be taken in account and treated in different ways. That is a strong argument for the need of patient orientated medicine, the so called personalized medicine. In the light of modern very sensitive methods like proteomics, nextgeneration-sequencing, digital-droplet-PCR and array technologies like NanoString it should be possible to test every tumour patient for the presence or absence of relevant mutations as well as miRNA and protein expression pattern to come up with the best possible individual treatment for each tumour patient.

Even if we have today a huge knowledge about signal transduction, regulation and interaction of different signal transduction pathways it seems that there still is at least partially lack in understanding the complex network of protein interaction in detail. Therefore further research is necessary to unravel all protein interactions and especially in the case of PI3K/AKT/mTOR pathway the effects of protein overexpression in the context of different cells and patients.

\section{Competing Interests}

The authors declare that they have no competing interests.

\section{References}

1. Ferlay J, Soerjomataram I, Dikshit R, Eser S, Mathers C, et al. (2015) Cancer incidence and mortality worldwide: sources, methods and major patterns in GLOBOCAN 2012. Int J Cancer 136: E359-386.

2. Jemal A, Siegel R, Xu J, Ward E (2010) Cancer statistics, 2010. CA Cancer J Clin 60: 277-300.

3. Metzger-Filho O1, Moulin C, D'Hondt V (2010) First-line systemic treatment of ovarian cancer: a critical review of available evidence and expectations for future directions. Curr Opin Oncol 22: 513-520.

4. Vivanco I, Sawyers CL (2002) The phosphatidylinositol 3-Kinase AKT pathway in human cancer. Nat Rev Cancer 2: 489-501.
5. Domin J, Pages F, Volinia S, Rittenhouse SE, Zvelebil MJ, et al. (1997) Cloning of a human phosphoinositide 3-kinase with a $\mathrm{C} 2$ domain that displays reduced sensitivity to the inhibitor wortmannin. Biochem J 326 : 139-147.

6. Saal LH, Holm K, Maurer M, Memeo L, Su T, et al. (2005) PIK3CA mutations correlate with hormone receptors, node metastasis, and ERBB2, and are mutually exclusive with PTEN loss in human breast carcinoma. Cancer Res 65: 2554-2559.

7. Petiot A, Ogier-Denis E, Blommaart EF, Meijer AJ, Codogno P (2000) Distinct classes of phosphatidylinositol 3'-kinases are involved in signaling pathways that control macroautophagy in HT-29 cells. J Biol Chem 275: 992-998.

8. Kondo Y, Kanzawa T, Sawaya R, Kondo S (2005) The role of autophagy in cancer development and response to therapy. Nat Rev Cancer 5: 726-734.

9. Roche S, Koegl M, Courtneidge SA (1994) The phosphatidylinositol 3-kinase alpha is required for DNA synthesis induced by some, but not all, growth factors. Proc Natl Acad Sci U S A 91: 9185-9189.

10. Wennström S, Hawkins P, Cooke F, Hara K, Yonezawa K, et al. (1994) Activation of phosphoinositide 3-kinase is required for PDGF-stimulated membrane ruffling. Curr Biol 4: 385-393.

11. Yao R, Cooper GM (1996) Growth factor-dependent survival of rodent fibroblasts requires phosphatidylinositol 3-kinase but is independent of pp70S6K activity. Oncogene 13: 343-351.

12. Toker A, Yoeli-Lerner $M(2006)$ Akt signaling and cancer: surviving but not moving on. Cancer Res 66: 3963-3966.

13. Künstle G, Laine J, Pierron G, Kagami Si S, Nakajima H, et al. (2002) Identification of Akt association and oligomerization domains of the Akt kinase coactivator TCL1. Mol Cell Biol 22: 1513-1525.

14. Engelman JA (2009) Targeting PI3K signalling in cancer: opportunities, challenges and limitations. Nat Rev Cancer 9: 550-562.

15. Fresno Vara JA, Casado E, de Castro J, Cejas P, Belda-Iniesta C, et al. (2004) PI3K/Akt signalling pathway and cancer. Cancer Treat Rev 30: 193204.

16. Shaw RJ, Cantley LC (2006) Ras, $\mathrm{PI}(3) \mathrm{K}$ and mTOR signalling controls tumour cell growth. Nature 441: 424-430.

17. Diaz-Padilla I, Duran I, Clarke BA, Oza AM (2012) Biologic rationale and clinical activity of mTOR inhibitors in gynecological cancer. Cancer Treat Rev 38: 767-775

18. Jung $\mathrm{CH}$, Ro $\mathrm{SH}$, Cao J, Otto NM, Kim DH (2010) mTOR regulation of autophagy. FEBS Lett 584: 1287-1295.

19. Wang CW, Klionsky DJ (2003) The molecular mechanism of autophagy. Mol Med 9: 65-76.

20. Santiskulvong C, Konecny GE, Fekete M, Chen KY, Karam A, et al. (2011) Dual targeting of phosphoinositide 3-kinase and mammalian target of rapamycin using NVP-BEZ235 as a novel therapeutic approach in human ovarian carcinoma. Clin Cancer Res 17: 2373-2384.

21. Shayesteh L, Lu Y, Kuo WL, Baldocchi R, Godfrey T, et al. (1999) PIK3CA is implicated as an oncogene in ovarian cancer. Nat Genet 21: 99-102.

22. Hennessy BT, Smith DL, Ram PT, Lu Y, Mills GB (2005) Exploiting the PI3K/ AKT pathway for cancer drug discovery. Nat Rev Drug Discov 4: 988-1004.

23. Bellacosa A, Kumar CC, Di Cristofano A, Testa JR (2005) Activation of AKT kinases in cancer: implications for therapeutic targeting. Adv Cancer Res 94: 29-86.

24. Manning BD, Cantley LC (2007) AKT/PKB signaling: navigating downstream. Cell 129: 1261-1274.

25. Engelman JA, Luo J, Cantley LC (2006) The evolution of phosphatidylinositol 3-kinases as regulators of growth and metabolism. Nat Rev Genet 7: 606619.

26. Kong D, Suzuki A, Zou TT, Sakurada A, Kemp LW, et al. (1997) PTEN1 is frequently mutated in primary endometrial carcinomas. Nat Genet 17: $143-144$.

27. Minaguchi T, Yoshikawa H, Oda K, Ishino T, Yasugi T, et al. (2001) PTEN mutation located only outside exons 5,6 , and 7 is an independent predictor of favorable survival in endometrial carcinomas. Clin Cancer Res 7: 26362642.

28. Meier F, Schittek B, Busch S, Garbe C, Smalley K, et al. (2005) The RAS/ RAF/MEK/ERK and PI3K/AKT signaling pathways present molecular targets for the effective treatment of advanced melanoma. Front Biosci 10: 2986-3001. 
29. Chang F, Lee JT, Navolanic PM, Steelman LS, Shelton JG, et al. (2003) Involvement of PI3K/Akt pathway in cell cycle progression, apoptosis, and neoplastic transformation: a target for cancer chemotherapy. Leukemia 17: 590-603.

30. Chang F, Steelman LS, Lee JT, Shelton JG, Navolanic PM, et al. (2003) Signal transduction mediated by the Ras/Raf/MEK/ERK pathway from cytokine receptors to transcription factors: potential targeting for therapeutic intervention. Leukemia 17: 1263-1293.

31. Chang F, Steelman LS, Shelton JG, Lee JT, Navolanic PM, et al. (2003) Regulation of cell cycle progression and apoptosis by the Ras/Raf/MEK/ ERK pathway (Review). Int J Oncol 22: 469-480.

32. Steelman LS, Chappell WH, Abrams SL, Kempf RC, Long J, et al. (2011) Roles of the Raf/MEK/ERK and PI3K/PTEN/Akt/mTOR pathways in controlling growth and sensitivity to therapy-implications for cancer and aging. Aging (Albany NY) 3: 192-222.

33. Frémin C, Meloche S (2010) From basic research to clinical development of MEK1/2 inhibitors for cancer therapy. J Hematol Oncol 3: 8 .

34. Huang W, Kessler DS, Erikson RL (1995) Biochemical and biological analysis of Mek1 phosphorylation site mutants. Mol Biol Cell 6: 237-245.

35. Tanoue T, Maeda R, Adachi M, Nishida E (2001) Identification of a docking groove on ERK and p38 MAP kinases that regulates the specificity of docking interactions. EMBO J 20: 466-479.

36. Crews CM, Alessandrini A, Erikson RL (1992) The primary structure of MEK, a protein kinase that phosphorylates the ERK gene product. Science 258: 478-480.

37. Ebisuya M, Kondoh K, Nishida E (2005) The duration, magnitude and compartmentalization of ERK MAP kinase activity: mechanisms for providing signaling specificity. J Cell Sci 118: 2997-3002.

38. Conway AM, Rakhit S, Pyne S, Pyne NJ (1999) Platelet-derived-growthfactor stimulation of the p42/p44 mitogen-activated protein kinase pathway in airway smooth muscle: role of pertussis-toxin-sensitive G-proteins, c-Src tyrosine kinases and phosphoinositide 3-kinase. Biochem J 337 : 171-177.

39. Cross DA, Alessi DR, Vandenheede JR, McDowell HE, Hundal HS, et al (1994) The inhibition of glycogen synthase kinase-3 by insulin or insulinlike growth factor 1 in the rat skeletal muscle cell line L6 is blocked by wortmannin, but not by rapamycin: evidence that wortmannin blocks activation of the mitogen-activated protein kinase pathway in L6 cells between Ras and Raf. Biochem J 303: 21-26.

40. Von Willebrand M, Jascur T, Bonnefoy-Bérard N, Yano H, Altman A, et al. (1996) Inhibition of phosphatidylinositol 3-kinase blocks T cell antigen receptor/CD3-induced activation of the mitogen-activated kinase Erk2. Eur J Biochem 235: 828-835.

41. Ferby IM, Waga I, Hoshino M, Kume K, Shimizu T (1996) Wortmannin inhibits mitogen-activated protein kinase activation by platelet-activating factor through a mechanism independent of p85/p110-type phosphatidylinosito 3-kinase. J Biol Chem 271: 11684-11688.

42. Furuta S, Hidaka E, Ogata A, Yokota S, Kamata T (2004) Ras is involved in the negative control of autophagy through the class I PI3-kinase. Oncogene 23: 3898-3904

43. Castellano E, Downward J (2011) RAS Interaction with PI3K: More Than Just Another Effector Pathway. Genes Cancer 2: 261-274.

44. Rommel C, Clarke BA, Zimmermann S, Nuñez L, Rossman R, et al. (1999) Differentiation stage-specific inhibition of the Raf-MEK-ERK pathway by Akt. Science 286: 1738-1741.

45. Zimmermann S, Moelling K (1999) Phosphorylation and regulation of Ra by Akt (protein kinase B). Science 286: 1741-1744.

46. Ma L, Chen Z, Erdjument-Bromage H, Tempst P, Pandolfi PP (2005) Phosphorylation and functional inactivation of TSC2 by Erk implications for tuberous sclerosis and cancer pathogenesis. Cell 121: 179-193.

47. Sunayama J, Matsuda K, Sato A, Tachibana K, Suzuki K, et al. (2010) Crosstalk between the PI3K/mTOR and MEK/ERK pathways involved in the maintenance of self-renewal and tumorigenicity of glioblastoma stemlike cells. Stem Cells 28: 1930-1939.

48. Shi Y, Hsu JH, Hu L, Gera J, Lichtenstein A (2002) Signal pathways involved in activation of p70S6K and phosphorylation of 4E-BP1 following exposure of multiple myeloma tumor cells to interleukin-6. J Biol Chem 277: 15712-15720.

49. Harrington LS, Findlay GM, Gray A, Tolkacheva T, Wigfield S, et al. (2004) The TSC1-2 tumor suppressor controls insulin-PI3K signaling via regulation of IRS proteins. J Cell Biol 166: 213-223.
50. Samuels Y, Velculescu VE (2004) Oncogenic mutations of PIK3CA in human cancers. Cell Cycle 3: 1221-1224.

51. Kurman RJ, Shih leM (2011) Molecular pathogenesis and extraovarian origin of epithelial ovarian cancer--shifting the paradigm. Hum Pathol 42: 918-931.

52. Vazquez F, Sellers WR (2000) The PTEN tumor suppressor protein: an antagonist of phosphoinositide 3-kinase signaling. Biochim Biophys Acta 1470: M21-35.

53. Wu X, Senechal K, Neshat MS, Whang YE, Sawyers CL (1998) The PTEN/ MMAC1 tumor suppressor phosphatase functions as a negative regulator of the phosphoinositide 3-kinase/Akt pathway. Proc Natl Acad Sci U S A 95: 15587-15591

54. Leslie NR, Gray A, Pass I, Orchiston EA, Downes CP (2000) Analysis of the cellular functions of PTEN using catalytic domain and C-terminal mutations: differential effects of C-terminal deletion on signalling pathways downstream of phosphoinositide 3-kinase. Biochem J 346 Pt 3: 827-833.

55. Dahia PL, Aguiar RC, Alberta J, Kum JB, Caron S, et al. (1999) PTEN is inversely correlated with the cell survival factor Akt/PKB and is inactivated via multiple mechanismsin haematological malignancies. Hum Mol Genet 8: 185-193.

56. Hashiguchi $\mathrm{Y}$, Tsuda H, Inoue T, Berkowitz RS, Mok SC (2006) PTEN expression in clear cell adenocarcinoma of the ovary. Gynecol Oncol 101: 71-75.

57. Carpten JD, Faber AL, Horn C, Donoho GP, Briggs SL, et al. (2007) A transforming mutation in the pleckstrin homology domain of AKT1 in cancer. Nature 448: 439-444.

58. McCubrey JA, Steelman LS, Chappell WH, Abrams SL, Montalto G, et al. (2012) Mutations and deregulation of Ras/Raf/MEK/ERK and PI3K/PTEN/ Akt/mTOR cascades which alter therapy response. Oncotarget 3: 954-987.

59. Ulkü AS, Schäfer R, Der CJ (2003) Essential role of Raf in Ras transformation and deregulation of matrix metalloproteinase expression in ovarian epithelial cells. Mol Cancer Res 1: 1077-1088.

60. Taylor V, Wong M, Brandts C, Reilly L, Dean NM, et al. (2000) 5' phospholipid phosphatase SHIP-2 causes protein kinase B inactivation and cell cycle arrest in glioblastoma cells. Mol Cell Biol 20: 6860-6871.

61. Fan Y, Wang L, Han X, Liu X, Ma H (2015) Rab25 is responsible for phosphoinositide 3-kinase/AKTâ€'mediated cisplatin resistance in human epithelial ovarian cancer cells. Mol Med Rep 11: 2173-2178.

62. Wang T, Li Y, Tuerhanjiang A1, Wang W1, Wu Z1, et al. (2014) Twist2 contributes to cisplatin-resistance of ovarian cancer through the AKT/GSK$3 \hat{l}^{2}$ signaling pathway. Oncol Lett 7: 1102-1108.

63. Wang Y, Tu Q, Yan W, Xiao D, Zeng Z, et al. (2015) CXC195 suppresses proliferation and inflammatory response in LPS-induced human hepatocellular carcinoma cells via regulating TLR4-MyD88-TAK1-mediated NF-Î'B and MAPK pathway. Biochem Biophys Res Commun 456: 373-379.

64. Levine DA, Bogomolniy F, Yee CJ, Lash A, Barakat RR, et al. (2005) Frequent mutation of the PIK3CA gene in ovarian and breast cancers. Clin Cancer Res 11: 2875-2878.

65. Chen R, Yang Q, Lee JD (2012) BMK1 kinase suppresses epithelialmesenchymal transition through the Akt/GSK3î ${ }^{2}$ signaling pathway. Cancer Res 72: 1579-1587.

66. Stewart DJ (2007) Mechanisms of resistance to cisplatin and carboplatin. Crit Rev Oncol Hematol 63: 12-31.

67. Lee S, Choi EJ, Jin C, Kim DH (2005) Activation of PI3K/Akt pathway by PTEN reduction and PIK3CA mRNA amplification contributes to cisplatin resistance in an ovarian cancer cell line. Gynecol Oncol 97: 26-34.

68. Gagnon V, Mathieu I, Sexton E, Leblanc K, Asselin E (2004) AKT involvement in cisplatin chemoresistance of human uterine cancer cells. Gynecol Oncol 94: 785-795.

69. Mondesire WH, Jian W, Zhang H, Ensor J, Hung MC, et al. (2004) Targeting mammalian target of rapamycin synergistically enhances chemotherapyinduced cytotoxicity in breast cancer cells. Clin Cancer Res 10: 7031-7042.

70. Engel JB, Schönhals T, Häusler S, Krockenberger M, Schmidt M, et al. (2011) Induction of programmed cell death by inhibition of AKT with the alkylphosphocholine perifosine in in vitro models of platinum sensitive and resistant ovarian cancers. Arch Gynecol Obstet 283: 603-610.

71. Benedetti V, Perego P, Luca Beretta G, Corna E, Tinelli S, et al. (2008) Modulation of survival pathways in ovarian carcinoma cell lines resistant to platinum compounds. Mol Cancer Ther 7: 679-687. 
Citation: Hahne JC (2015) Platinum-resistance and AKT Over-expression in Ovarian Cancer. Int J Gynecol Clin Pract 2: 110. doi: http://dx.doi.org/10.15344/2394$4986 / 2015 / 110$

72. Hahne JC, Honig A, Meyer SR, Gambaryan S, Walter U, et al. (2012) Downregulation of AKT reverses platinum resistance of human ovarian cancers in vitro. Oncol Rep 28: 2023-2028.

73. Hahne JC, Meyer SR, Gambaryan S, Walter U, Dietl J, et al. (2013) Immune escape of AKT overexpressing ovarian cancer cells. Int $\mathrm{J}$ Oncol 42: $1630-1635$.

74. Honig A, Hahne JC, Meyer S, Kranke P, Häusler S, et al. (2012) PI3K inhibitor D-116883 is effective in in vitro models of ovarian cancer. Anticancer Res 32: 2035-2041.

75. Eckstein N (2011) Platinum resistance in breast and ovarian cancer cel lines. J Exp Clin Cancer Res 30: 91.

76. Cheng JQ, Lindsley CW, Cheng GZ, Yang H, Nicosia SV (2005) The Akt/ PKB pathway: molecular target for cancer drug discovery. Oncogene 24: 7482-7492.

77. Hövelmann S, Beckers TL, Schmidt M (2004) Molecular alterations in apoptotic pathways after PKB/Akt-mediated chemoresistance in $\mathrm{NCl} \mathrm{H} 460$ cells. Br J Cancer 90: 2370-2377.

78. Westfall SD, Skinner MK (2005) Inhibition of phosphatidylinositol 3-kinase sensitizes ovarian cancer cells to carboplatin and allows adjunct chemotherapy treatment. Mol Cancer Ther 4: 1764-1771.

79. Testa JR, Bellacosa A (2001) AKT plays a central role in tumorigenesis. Proc Natl Acad Sci U S A 98: 10983-10985.

80. Nicholson KM, Anderson NG (2002) The protein kinase B/Akt signalling pathway in human malignancy. Cell Signal 14: 381-395.

81. Dobbin ZC, Landen CN (2013) The Importance of the PI3K/AKT/MTOR Pathway in the Progression of Ovarian Cancer. Int J Mol Sci 14: 8213-8227.

82. Pink RC, Samuel P, Massa D, Caley DP, Brooks SA, et al. (2015) The passenger strand, miR-21-3p, plays a role in mediating cisplatin resistance in ovarian cancer cells. Gynecol Oncol 137: 143-151.

83. Zhou Y, Chen Q, Qin R, Zhang K, Li H (2014) MicroRNA-449a reduces cel survival and enhances cisplatin-induced cytotoxicity via downregulation of NOTCH1 in ovarian cancer cells. Tumour Biol 35: 12369-12378.

84. Chen S, Chen X, Xiu YL, Sun KX, Zong ZH, et al. (2014) microRNA 490-3P enhances the drug-resistance of human ovarian cancer cells. J Ovarian Res 7: 84 .

85. Yan M, Chen C, Gong W, Yin Z, Zhou L, et al. (2015) miR-21-3p regulates cardiac hypertrophic response by targeting histone deacetylase-8. Cardiovasc Res 105: 340-352.

86. Osanto S, Qin Y, Buermans HP, Berkers J, Lerut E, et al. (2012) Genomewide microRNA expression analysis of clear cell renal cell carcinoma by next generation deep sequencing. PLoS One 7: e38298.

87. Huang Y, Dai Y, Yang J, Chen T, Yin Y, et al. (2009) Microarray analysis of microRNA expression in renal clear cell carcinoma. Eur J Surg Oncol 35: 1119-1123.

88. Chow TF, Youssef YM, Lianidou E, Romaschin AD, Honey RJ, et al (2010) Differential expression profiling of microRNAs and their potential involvement in renal cell carcinoma pathogenesis. Clin Biochem 43: 150158.

89. Youssef YM, White NM, Grigull J, Krizova A, Samy C, et al. (2011) Accurate molecular classification of kidney cancer subtypes using microRNA signature. Eur Urol 59: 721-730.

90. Yao Y, Ma J, Xue Y, Wang P, Li Z, et al. (2015) MiR-449a exerts tumorsuppressive functions in human glioblastoma by targeting Myc-associated zinc-finger protein. Mol Oncol 9: 640-656.

91. Hales EC, Taub JW, Matherly LH (2014) New insights into Notch1 regulation of the PI3K-AKT-mTOR1 signaling axis: targeted therapy of $\hat{i}^{3}$-secretase inhibitor resistant T-cell acute lymphoblastic leukemia. Cell Signal 26: 149161.

92. Cheng Q, Yi B, Wang A, Jiang X (2013) Exploring and exploiting the fundamental role of microRNAs in tumor pathogenesis. Onco Targets Ther 6: 1675-1684.

93. Beaufort CM, Helmijr JC, Piskorz AM, Hoogstraat M, Ruigrok-Ritstier K, et al. (2014) Ovarian cancer cell line panel (OCCP): clinical importance of in vitro morphological subtypes. PLoS One 9: e103988.

94. Behrens BC, Hamilton TC, Masuda H, Grotzinger KR, Whang-Peng J, et al. (1987) Characterization of a cis-diamminedichloroplatinum(II)-resistant human ovarian cancer cell line and its use in evaluation of platinum analogues. Cancer Res 47: 414-418.
95. Hahne JC, Kurz A, Meyer SR, Dietl J, Engel JB, et al. (2015) Anti-tumour activity of phosphoinositide-3-kinase antagonist AEZS-126 in models of ovarian cancer. Arch Gynecol Obstet 291: 131-141.

96. Ali AY, Kim JY, Pelletier JF, Vanderhyden BC, Bachvarov DR, et al. (2014) Akt confers cisplatin chemoresistance in human gynecological carcinoma cells by modulating PPM1D stability. Mol Carcinog.

97. Bao L, Jaramillo MC, Zhang Z, Zheng Y, Yao M, et al. (2015) Induction of autophagy contributes to cisplatin resistance in human ovarian cancer cells. Mol Med Rep 11: 91-98.

98. Zhao JX, Liu H, Lv J, Yang XJ (2014) Wortmannin enhances cisplatininduced apoptosis in human ovarian cancer cells in vitro. Eur Rev Med Pharmacol Sci 18: 2428-2434.

99. Liu G, Du P, Zhang Z (2014) Myeloid Differentiation Factor 88 Promotes Cisplatin Chemoresistance in Ovarian Cancer. Cell Biochem Biophys 71: 963-969.

100. He G, Kuang J, Khokhar AR, Siddik ZH (2011) The impact of S- and G2-checkpoint response on the fidelity of $\mathrm{G} 1$-arrest by cisplatin and its comparison to a non-cross-resistant platinum(IV) analog. Gynecol Oncol 122: 402-409.

101. Hayakawa J, Ohmichi M, Kurachi H, Kanda Y, Hisamoto K, et al. (2000) Inhibition of BAD phosphorylation either at serine 112 via extracellular signal-regulated protein kinase cascade or at serine 136 via Akt cascade sensitizes human ovarian cancer cells to cisplatin. Cancer Res 60: 59885994.

102. Betito S, Cuvillier O (2006) Regulation by sphingosine 1-phosphate of Bax and Bad activities during apoptosis in a MEK-dependent manner. Biochem Biophys Res Commun 340: 1273-1277.

103. Yang X, Fraser M, Moll UM, Basak A, Tsang BK (2006) Akt-mediated cisplatin resistance in ovarian cancer: modulation of p53 action on caspasedependent mitochondrial death pathway. Cancer Res 66: 3126-3136.

104. Fraser M, Bai T, Tsang BK (2008) Akt promotes cisplatin resistance in human ovarian cancer cells through inhibition of p53 phosphorylation and nuclear function. Int J Cancer 122: 534-546.

105. Arafa el-SA, Zhu Q, Barakat BM, Wani G, Zhao Q, et al. (2009) Tangeretin sensitizes cisplatin-resistant human ovarian cancer cells through downregulation of phosphoinositide 3-kinase/Akt signaling pathway. Cancer Res 69: 8910-8917.

106. Kolasa IK, Rembiszewska A, Felisiak A, Ziolkowska-Seta I, Murawska M, et al. (2009) PIK3CA amplification associates with resistance to chemotherapy in ovarian cancer patients. Cancer Biol Ther 8: 21-26.

107. Woenckhaus J, Steger K, Sturm K, Münstedt K, Franke FE, et al. (2007) Prognostic value of PIK3CA and phosphorylated AKT expression in ovarian cancer. Virchows Arch 450: 387-395.

108. Sasano T, Mabuchi S, Kuroda H, Kawano M, Matsumoto Y, et al. (2015) Preclinical Efficacy for AKT Targeting in Clear Cell Carcinoma of the Ovary. Mol Cancer Res 13: 795-806.

109. Marsh Rde W, Rocha Lima CM, Levy DE, Mitchell EP, Rowland KM Jr, et al. (2007) A phase II trial of perifosine in locally advanced, unresectable, or metastatic pancreatic adenocarcinoma. Am J Clin Oncol 30: 26-31.

110. Leighl NB, Dent S, Clemons M, Vandenberg TA, Tozer R, et al. (2008) A Phase 2 study of perifosine in advanced or metastatic breast cancer. Breast Cancer Res Treat 108: 87-92.

111. Snyder EL, Bailey D, Shipitsin M, Polyak K, Loda M (2009) Identification of CD44v6(+)/CD24- breast carcinoma cells in primary human tumors by quantum dot-conjugated antibodies. Lab Invest 89: 857-866.

112. Argiris A, Cohen E, Karrison T, Esparaz B, Mauer A, et al. (2006) A phase II trial of perifosine, an oral alkylphospholipid, in recurrent or metastatic head and neck cancer. Cancer Biol Ther 5: 766-770.

113. Knowling M, Blackstein M, Tozer R, Bramwell V, Dancey J, et al. (2006) A phase II study of perifosine (D-21226) in patients with previously untreated metastatic or locally advanced soft tissue sarcoma: A National Cancer Institute of Canada Clinical Trials Group trial. Invest New Drugs 24: 435439.

114. Posadas EM, Gulley J, Arlen PM, Trout A, Parnes HL, et al. (2005) A phase II study of perifosine in androgen independent prostate cancer. Cancer Biol Ther 4: 1133-1137.

115. Ernst DS, Eisenhauer E, Wainman N, Davis M, Lohmann R, et al. (2005) Phase II study of perifosine in previously untreated patients with metastatic melanoma. Invest New Drugs 23: 569-575. 
Citation: Hahne JC (2015) Platinum-resistance and AKT Over-expression in Ovarian Cancer. Int J Gynecol Clin Pract 2: 110. doi: http://dx.doi.org/10.15344/2394$4986 / 2015 / 110$

116. Vink SR, Schellens JH, Beijnen JH, Sindermann H, Engel J, et al. (2006) Phase I and pharmacokinetic study of combined treatment with perifosine and radiation in patients with advanced solid tumours. Radiother Oncol 80: 207-213.

117. Caligiuri MA (2008) Human natural killer cells. Blood 112: 461-469.

118. Vivier E, Raulet DH, Moretta A, Caligiuri MA, Zitvogel L, et al. (2011) Innate or adaptive immunity? The example of natural killer cells. Science 331 : 44-49.

119. Lanier LL (2008) Up on the tightrope: natural killer cell activation and inhibition. Nat Immunol 9: 495-502.

120. Moretta L, Biassoni R, Bottino C, Mingari MC, Moretta A (2000) Human NKcell receptors. Immunol Today 21: 420-422.

121. Lanier LL (2005) NK cell recognition. Annu Rev Immunol 23: 225-274.

122. Dunn GP, Bruce AT, Ikeda H, Old LJ, Schreiber RD (2002) Cancer immunoediting: from immunosurveillance to tumor escape. Nat Immunol 3: 991-998.

123. Orr MT, Lanier LL (2010) Natural killer cell education and tolerance. Cell 142: 847-856.

124. Smyth MJ, Dunn GP, Schreiber RD (2006) Cancer immunosurveillance and immunoediting: the roles of immunity in suppressing tumor development and shaping tumor immunogenicity. Adv Immunol 90: 1-50.

125. Zhang $Y$, Wang $X$, Yang H, Liu H, Lu Y, et al. (2013) Kinase AKT controls innate immune cell development and function. Immunology 140: 143-152.

126. Hawkins PT, Stephens LR (2015) PI3K signalling in inflammation. Biochim Biophys Acta 1851: 882-897.

127. Soliman GA (2013) The role of mechanistic target of rapamycin (mTOR) complexes signaling in the immune responses. Nutrients 5: 2231-2257.

128. Dituri F, Mazzocca A, Giannelli G, Antonaci S (2011) PI3K functions in cancer progression, anticancer immunity and immune evasion by tumors. Clin Dev Immunol 2011: 947858.

129. Bhoopathi P, Quinn BA, Gui Q, Shen XN, Grossman SR, et al. (2014) Pancreatic cancer-specific cell death induced in vivo by cytoplasmicdelivered polyinosine-polycytidylic acid. Cancer Res 74: 6224-6235.

130. Engel JB, Honig A, Kapp M, Hahne JC, Meyer SR, et al. (2014) Mechanisms of tumor immune escape in triple-negative breast cancers (TNBC) with and without mutated BRCA 1. Arch Gynecol Obstet 289: 141-147.

131. Noh KH, Kang TH, Kim JH, Pai SI, Lin KY, et al. (2009) Activation of Akt as a mechanism for tumor immune evasion. Mol Ther 17: 439-447.

132. Bellucci R, Nguyen HN, Martin A, Heinrichs S, Schinzel AC, et al. (2012) Tyrosine kinase pathways modulate tumor susceptibility to natural killer cells. J Clin Invest 122: 2369-2383.

133. Boutet P, Agüera-González S, Atkinson S, Pennington CJ, Edwards DR et al. (2009) Cutting edge: the metalloproteinase ADAM17/TNF-alphaconverting enzyme regulates proteolytic shedding of the $\mathrm{MHC}$ class I-related chain B protein. J Immunol 182: 49-53.

134. Waldhauer I, Goehlsdorf D, Gieseke F, Weinschenk T, Wittenbrink M, et al (2008) Tumor-associated MICA is shed by ADAM proteases. Cancer Res 68: 6368-6376.

135. Okita R, Mougiakakos D, Ando T, Mao Y, Sarhan D, et al. (2012) HER2/ HER3 signaling regulates NK cell-mediated cytotoxicity via MHC class I chain-related molecule $A$ and $B$ expression in human breast cancer cell lines. J Immunol 188: 2136-2145.

136. Altomare DA, Wang HQ, Skele KL, De Rienzo A, Klein-Szanto AJ, et al (2004) AKT and mTOR phosphorylation is frequently detected in ovarian cancer and can be targeted to disrupt ovarian tumor cell growth. Oncogene 23: $5853-5857$

137. Nakayama K, Nakayama N, Kurman RJ, Cope L, Pohl G, et al. (2006) Sequence mutations and amplification of PIK3CA and AKT2 genes in purified ovarian serous neoplasms. Cancer Biol Ther 5: 779-785.

138. Campbell IG, Russell SE, Choong DY, Montgomery KG, Ciavarella ML, et al. (2004) Mutation of the PIK3CA gene in ovarian and breast cancer. Cancer Res 64: 7678-7681.

139. Kuo KT, Mao TL, Jones S, Veras E, Ayhan A, et al. (2009) Frequent activating mutations of PIK3CA in ovarian clear cell carcinoma. Am J Pathol 174: 1597-1601.

140. Matulonis UA, Hirsch M, Palescandolo E, Kim E, Liu J, et al. (2011) High throughput interrogation of somatic mutations in high grade serous cancer of the ovary. PLoS One 6: e24433. 